\title{
DISSECTION AND ELECTROPHORETIC PROTEIN ANALYSIS OF SINGLE MUSCLE FIBERS FROM HISTOLOGICALLY IDENTIFIED FREEZE-DRIED SECTIONS: APPLICATION TO MUSCLE FIBERS WITH RIMMED VACUOLES
}

\author{
ITARU TOYOSHIMA ${ }^{1,2}$, KEIKO TANAKA ${ }^{1,2}$, NOBUYOSHI FUKUHARA ${ }^{1}$, \\ TOSHIHIDE KUMAMOTO $^{1}$ and TADASHI MIYATAKE ${ }^{1}$ \\ ${ }^{1}$ Department of Neurology, and ${ }^{2}$ Neurochemistry, Brain Research Institute, Niigata University, Asahimachi, \\ Niigata 951, Japan
}

\begin{abstract}
A new method for analysing proteins from histologically identified single muscle fibers is presented. Each fiber in serial freeze-dried sections is identified in reference to consecutive stained sections before dissection. Dissected single fibers are lysed and electrophoresed. Only three and fifty pieces of $30 \mu \mathrm{m}$ cross section of muscle fiber were sufficient for sodium dodecyl sulfate (SDS)-gel electrophoresis and twodimensional gel electrophoresis, respectively. We applied this method to the muscle fibers with rimmed vacuoles, and found an increase of a $55 \mathrm{kDa}$ protein, which was identified as desmin.
\end{abstract}

Since Dubowitz and Brooke first described the 'rimmed vacuole' in oculopharyngeal dystrophy in 1973 (3), a number of reports have noted the presence of rimmed vacuoles in the muscle in various neuromuscular diseases $(5,9,10,15)$. Recent reports on the distal myopathy $(4,15)$ showed an increase of desmin in these muscle fibers. However, these authors electrophoresed the homogenates of the whole muscle, and it was uncertain whether their observation was related to the presence of rimmed vacuoles, since these vacuoles were found only in a small number of fibers. It is essential to analyse single muscle fibers.

Analyses of single fibers have been performed on specimens obtained by teasing of either freeze-dried $(2,21)$ or fresh $(8,14,24,25)$ muscle fibers. But the teasing and subsequent characterization of the fibers is time-consuming, especially when pathological changes are observed only in a small proportion of fibers. It is desirable to develop a method which allows us to dissect single muscle fibers which are histologically well-defined before dissection.
In this paper, we describe a new method which fulfills these requirements and we describe the results of analysis of single muscle fibers with rimmed vacuoles obtained from patients with distal myopathy and a related disorder.

\section{MATERIALS AND METHODS}

Six biopsy specimens of the muscle, namely, three from the patients with distal myopathy with rimmed vacuoles, one from a patient with Kearns-Sayre-like syndrome with rimmed vacuoles (23), and two normal controls, were analysed (Table 1).

A diagram of the procedure is shown in Fig. 1.

\section{Freeze-drying}

Specimens were freeze-dried essentially by the method of Lowry and Passonneau (13). Tissues were frozen rapidly in isopentane-dry ice and stored at $-80^{\circ} \mathrm{C}$ in stoppered tubes. Fifteen to 30 consecutive serial cross sections of 10 and 30 $\mu \mathrm{m}$ in thickness were cut in a cryostat. Ten 
Table 1 Subjects

\begin{tabular}{|c|c|c|c|c|}
\hline & Age & Sex & Clinical diagnosis & Muscle \\
\hline Patient 1 & 32 & M & Distal myopathy & Biceps brachii \\
\hline 2 & 26 & M & Distal myopathy & Quadriceps femoris \\
\hline 3 & 25 & $M$ & Distal myopathy & Tibialis anterior \\
\hline 4 & 22 & $M$ & $\begin{array}{l}\text { Kearns-Sayre-like syndrome } \\
\text { with rimmed vacuoles }\end{array}$ & Quadriceps femoris \\
\hline Control 1 & 43 & M & Psychogenic reaction & Quadriceps femoris \\
\hline 2 & 25 & $\mathrm{~F}$ & Psychogenic reaction & Quadriceps femoris \\
\hline
\end{tabular}

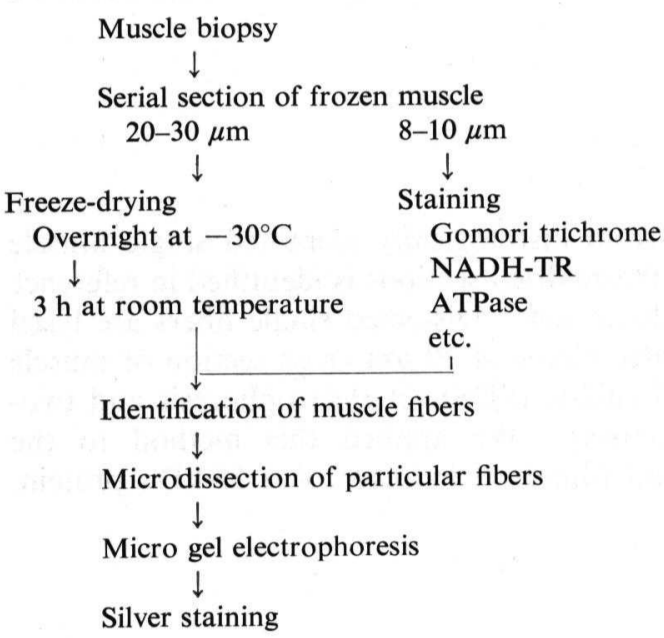

Fig. 1 Diagram of the procedure

sections were used for histological examination. Thirty micrometer sections were dried overnight at $-30^{\circ} \mathrm{C}$ in a vacuum tube (13), and further dried for $3 \mathrm{~h}$ at room temperature. They were stored at $-20^{\circ} \mathrm{C}$ in vacuum until use.

\section{Staining}

Ten micrometer sections were stained with the usual methods, namely, Gomori trichrome staining, NADH-TR staining, ATPase staining, and so on.

\section{Identification and Dissection of Single Muscle Fibers}

Freeze-dried sections were warmed to room temperature in the vacuum tube and picked out in a dry atmosphere and examined under a dissecting microscope. By comparing with stained sections, we determined whether each muscle fiber in the freeze-dried sections had rimmed vacuoles or not (Fig. 2).

Particular fibers in the consecutive freezedried sections were dissected from three sections. A hand-made microknife and hair point were used to separate and to pick up muscle fibers from surrounding connective tissues. Specimens were lysed in a modified Laemmli's sample buffer (11).

\section{Microelectrophoresis}

Sodium dodecyl sulfate (SDS)-gel electrophoresis using the system of Laemmli (11) was performed on $3 \mathrm{~cm}$ long, 7.5-15\% linear gradient acrylamide gels. Two-dimensional gel electrophoresis $(1,18)$ was performed on $4 \times 3$ or $4 \times 6 \mathrm{~cm}$ (width $\times$ length) gels. In isoelectric

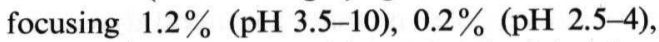
$0.4 \%$ (pH 5-7) and $0.4 \%$ (pH 9-11) of Ampholine (LKB) was used.

\section{Silver Staining}

Oakley's method (16) was modified to improve the sensitivity and to reduce the background (Table 2). All solutions except the running buffer were treated with Milipore filters (pore size, $1 \mu \mathrm{m}$ ).

\section{RESULTS}

\section{Appearance of Muscle Fibers with Rimmed Vacuoles in Freeze-dried Tissue}

The fibers which seemed to be vacuolated in the sections stained with Gomori trichrome had various appearances in the freeze-dried sections, and apparently were not vacuolated in general (Fig. 2). Vacuoles appeared to be formed in the staining process. 

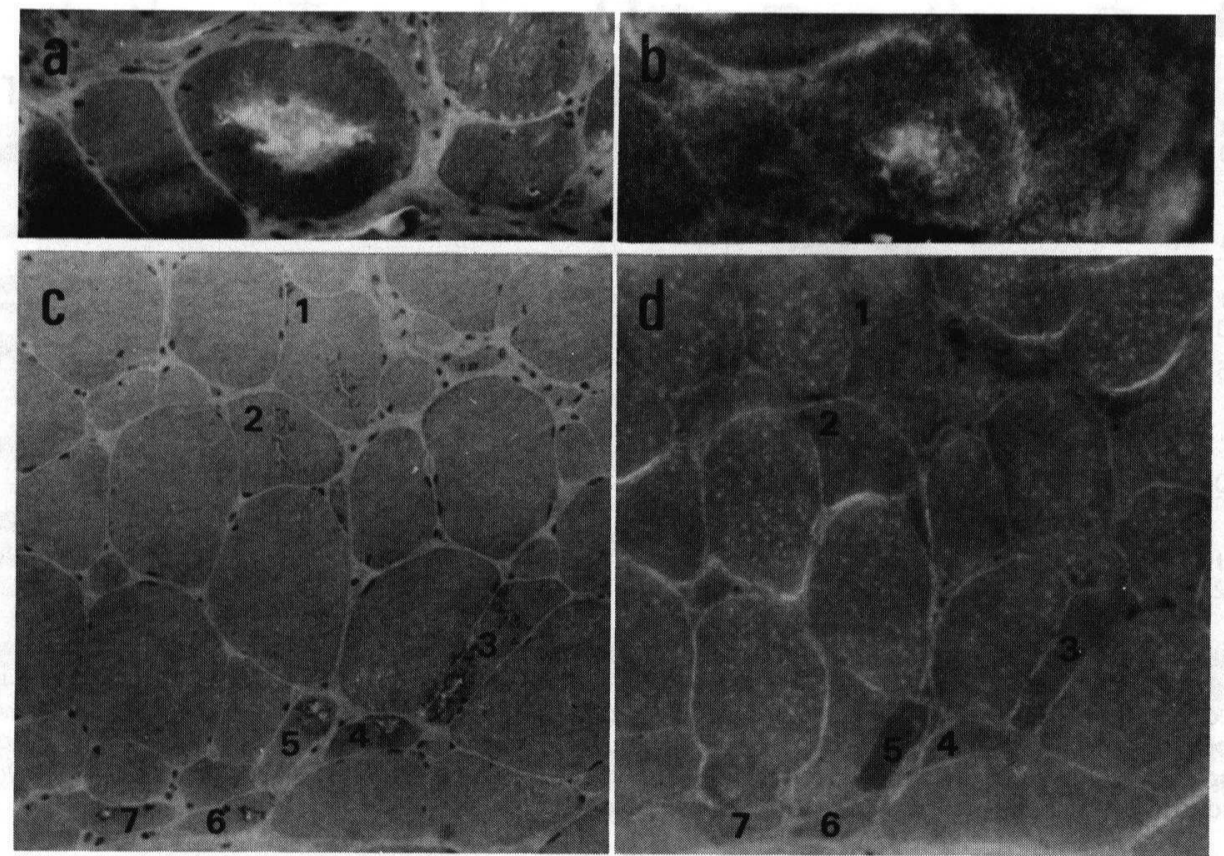

Fig. 2 Comparison of freeze-dried sections of muscle fibers (b, d) with the consecutive ones stained with Gomori trichrome $(\mathrm{a}, \mathrm{c})$. The specimens in $(\mathrm{a}, \mathrm{b})$ and $(\mathrm{c}, \mathrm{d})$ were obtained from cases No. 1 and No. 4, respectively. Fibers with rimmed vacuoles were identified and numbered. $\times 100$

Table 2 Procedure for Modified Silver Staining

\begin{tabular}{|c|c|c|c|}
\hline Step & \multicolumn{2}{|l|}{ Solution } & Time \\
\hline 1. & \multicolumn{2}{|l|}{$50 \%$ trichloroacetic acid (fresh) } & $1 \mathrm{~h}$ \\
\hline 2. & \multicolumn{2}{|l|}{$50 \%$ methanol, $10 \%$ acetic acid } & Overnight \\
\hline 3. & \multicolumn{2}{|l|}{$10 \%$ ethanol } & 5 min, 3 times \\
\hline 4. & \multicolumn{2}{|l|}{$10 \%$ glutaraldehyde (fresh) } & $1 \mathrm{~h}$ \\
\hline 5. & \multicolumn{2}{|l|}{$10 \%$ ethanol } & $10 \mathrm{~min}, 4$ times \\
\hline \multirow[t]{6}{*}{6.} & \multicolumn{2}{|l|}{ Diamine (fresh) } & $15 \mathrm{~min}$ \\
\hline & $19.4 \%$ silver nitrate & $4 \mathrm{ml}$ & \\
\hline & \multicolumn{2}{|c|}{$\begin{array}{l}0.36 \% \text { sodium hydroxide } 21 \mathrm{ml} \\
\text { Conc. ammonium hydroxide } 1.3 \mathrm{ml}\end{array}$} & \\
\hline & \multicolumn{2}{|c|}{ Conc. ammonium hydroxide $1.3 \mathrm{ml}$} & \\
\hline & $100 \%$ ethanol & $10 \mathrm{ml}$ & \\
\hline & Distilled water added to & $100 \mathrm{ml}$ & \\
\hline 7. & \multicolumn{2}{|l|}{$10 \%$ ethanol } & $1 \mathrm{~min}, 2$ times \\
\hline \multirow[t]{5}{*}{8.} & \multicolumn{2}{|l|}{ Reducer } & $3-10 \mathrm{~min}$ \\
\hline & \multicolumn{2}{|l|}{$3.7 \%$ formaldehyde $2.5 \mathrm{ml}$} & \\
\hline & \multirow{3}{*}{\multicolumn{2}{|c|}{$\begin{array}{lr}\text { Citric acid } & 25 \mathrm{mg} \\
100 \% \text { ethanol } & 50 \mathrm{ml} \\
\text { Distilled water } & 450 \mathrm{ml}\end{array}$}} & \\
\hline & & & \\
\hline & & & \\
\hline 9. & \multicolumn{2}{|l|}{ Wash in distilled water } & Overnight \\
\hline 10. & \multicolumn{2}{|l|}{ Drying } & \\
\hline
\end{tabular}




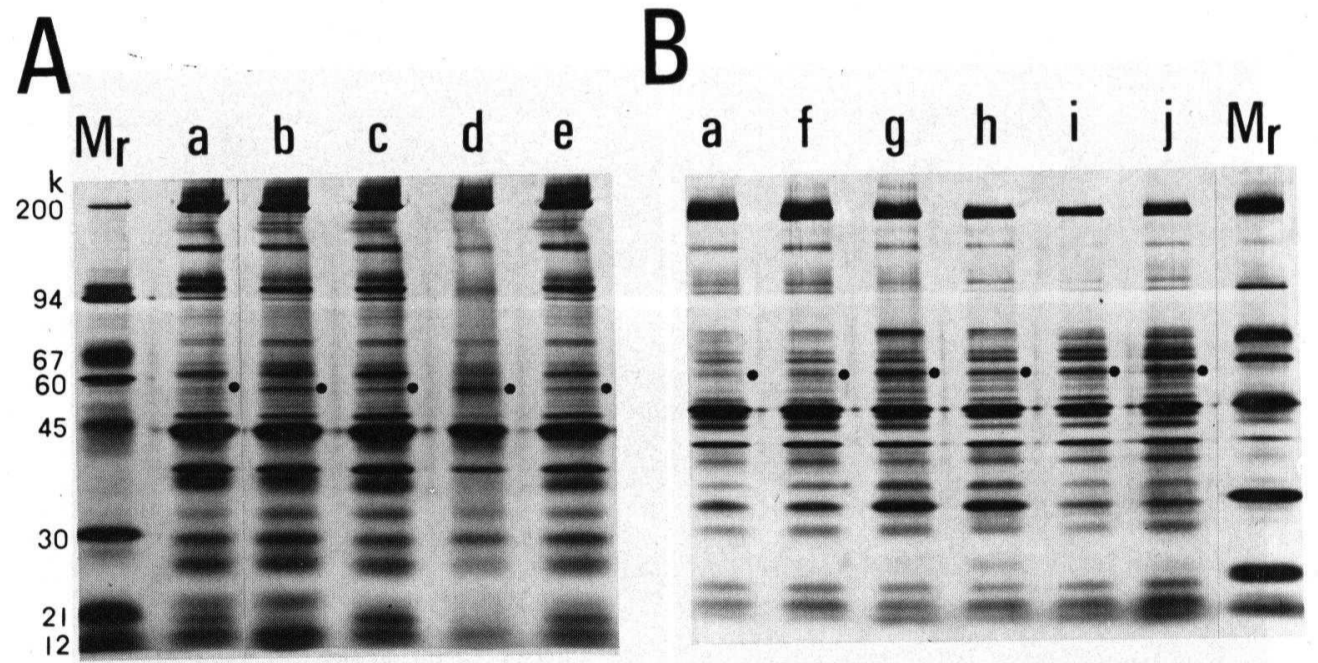

Fig. 3 SDS-gel electrophoresis of proteins of single muscle fibers. A and B were electrophoresed separately. Lane Aa, Ba: control No. 1; lanes b and c: patient No. 1; lanes d and e: patient No. 2; lane $\mathrm{f}$ : control No. 2; lanes g and $\mathrm{h}$ : patient No. 3; lanes i and $\mathrm{j}$ : patient No. 4. Lanes b, d, g, and i: muscle fibers with rimmed vacuoles; lanes $\mathrm{c}, \mathrm{e}, \mathrm{h}$, and $\mathrm{j}$ : muscle fibers without rimmed vacuoles. Lanes at both ends are the markers of molecular weight. Numbers indicate molecular weight (kilodaltons). Dots indicate the $55 \mathrm{kDa}$ protein, the amount of which was increased in the specimens from patients.

\section{SDS-Gel Electrophoresis of Proteins of Single Muscle Fibers}

Samples dissected from three sections of each single fiber were lysed in the buffer containing SDS and electrophoresed. Altogether, 30 fibers from four patients and two controls were analysed.

Each sample showed many bands (Fig. 3, A and $B$ ), most of which were identified by comigration of purified proteins $(17,20)$. Identification of these bands will be described elsewhere. The samples from patients showed patterns similar to those of the controls (Fig. 3, Aa, Ba and Bf), irrespective of the presence or absence of rimmed vacuoles, except in a few bands. Among these bands, only the band of $55 \mathrm{kDa}$ protein increased constantly in all samples from patients; the others were variable. The increase of $55 \mathrm{kDa}$ protein was larger in the fibers with rimmed vacuoles (Fig. 3, b, d, g and i) than in the ones without rimmed vacuoles (Fig. $3, \mathrm{c}, \mathrm{e}, \mathrm{h}$ and $\mathrm{j}$ ). This increase was further augmented when the fibers were atrophic in the stained sections (Fig. 3d).

\section{Identification of $55 \mathrm{kDa}$ Protein by Two- dimensional Gel Electrophoresis}

A portion of the section containing some 200 fibers was cut out and subjected to two-dimensional gel electrophoresis. Lower gels in the second dimension were $6 \mathrm{~cm}$ long. Fig. 4 shows the two-dimensional gel pattern of patient No. 3 (d), together with that of a control (c) and the SDS-gel patterns of the same specimens $(\mathrm{a}, \mathrm{b})$ run on the same gel. The $55 \mathrm{kDa}$ protein in the two-dimensional gels was identified by comparing it with corresponding SDS-gel patterns (arrows). SDS-gels again show an increase of the $55 \mathrm{kDa}$ proteins, which show three spots in the acidic region and diffuse ones in the alkaline region in two-dimensional gels. Three acidic spots at isoelectric points near $\alpha$-actin were denser in the gel from affected muscle fibers than in the control. These spots would correspond to desmin, judging from their molecular weight and isoelectric points $(6,12)$.

Further, alkaline proteins were examined with non-equilibrated two-dimensional gel electrophoresis (19), and no obvious increase of 55 $\mathrm{kDa}$ proteins other than desmin was observed.

\section{Two-Dimensional Gel Electrophoresis of Muscle Fibers with Rimmed Vacuoles}

Muscle fibers obtained from patients No. 2 and No. 3 were further analysed with two-dimensional gel electrophoresis. Some 50 fibers with rimmed vacuoles from one $30 \mu \mathrm{m}$ thick section 


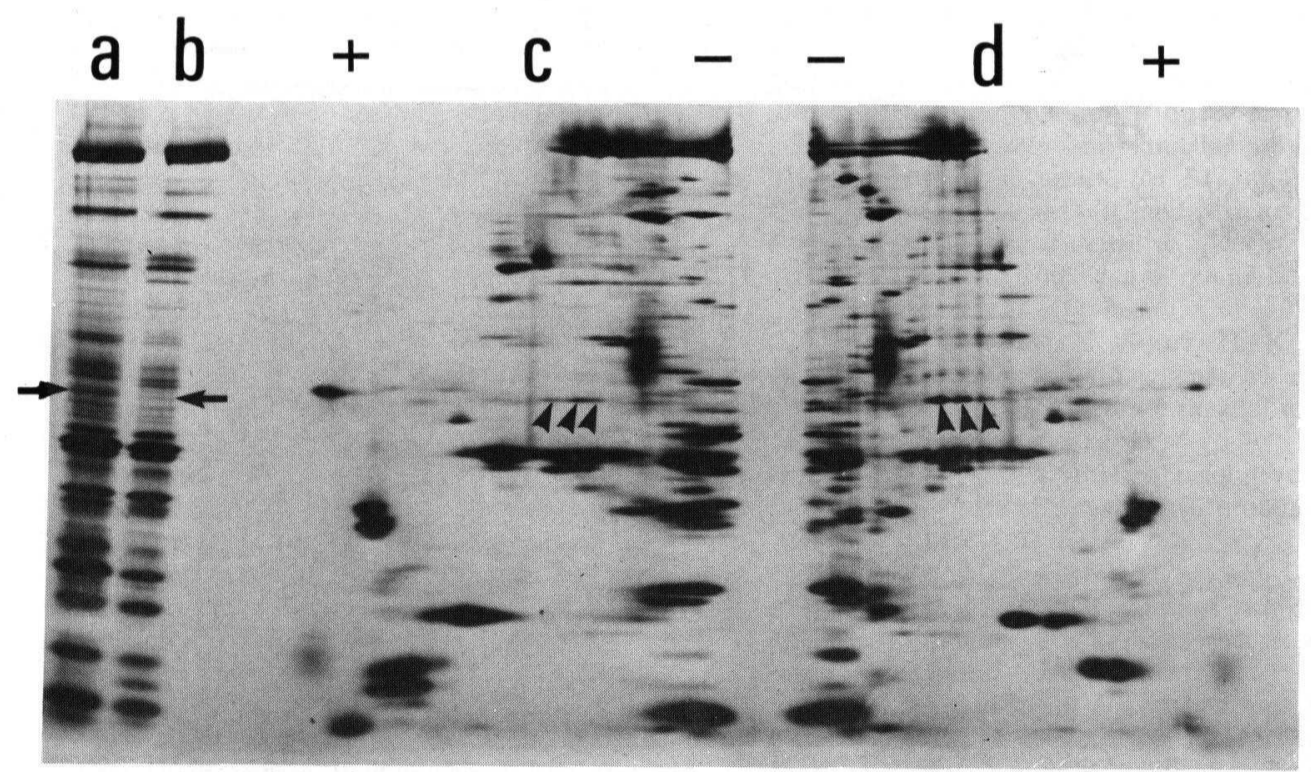

Fig. 4 Identification of 55 kDa protein. a and d: patient No. 3; b and c: control No. 1; a and b: SDSgel electrophoresis; $\mathrm{c}$ and $\mathrm{d}$ : two-dimensional gel electrophoresis. Arrows indicate $55 \mathrm{kDa}$ protein. Arrowheads indicate the spots considered to be desmin.

were collected and electrophoresed on $4 \times 3 \mathrm{~cm}$ gels. Fig. 5 shows the two-dimensional gels of the fibers with rimmed vacuoles (a), and without rimmed vacuoles (b) from patient No. 3. These gel patterns are essentially the same. As for desmin (arrowheads) the result in two-dimensional gel is consistent with that observed in SDS gel (Fig. 3).

\section{DISCUSSION}

\section{Advantages of the New Method}

There are some groups of muscle diseases where only a small proportion of muscle fibers show morphological changes. In other muscle diseases, a large proportion of muscle fibers are affected and different fibers in the same tissue section show different morphological changes. It is desirable to analyse the same single fiber both biochemically and morphologically.

So far single fiber analyses have been done on fibers obtained by teasing, and morphological examination has been done only after teasing. This method is exceedingly time-consuming when the proportion of affected fibers is small. In contrast, the method described here requires much less time and the least quantity of specimen, since the examination of consecutive stained sections indicates which fiber should be dissected from freeze-dried sections.

The use of freeze-dried specimen has some advantages over the use of fresh muscle. First, we can perform the examination at any time, since the specimen can be frozen immediately after biopsy and stored for more than several months at $-80^{\circ} \mathrm{C}$ without degradation of proteins. Second, since cytosol proteins are retained in freeze-dried specimens, it is possible to analyse the total proteins contained in the muscle fiber, and myofibrillar and cytosol proteins separately (21).

Though a detailed comparison has not yet been made, SDS and two-dimensional gel electrophoreses of the homogenates of fresh muscle, frozen muscle, and freeze-dried muscle showed almost the same patterns, which were similar to the published data $(7,8,14)$.

\section{Increase of $55 \mathrm{kDa}$ Protein}

This is the first report on the analysis of proteins in single muscle fibers with rimmed vacuoles. The $55 \mathrm{kDa}$ protein considered to be desmin was increased in the fibers both with and without rimmed vacuoles obtained from all four patients. This suggests that desmin is related to the degenerative process in distal myopathy and its related disorders. Increase of desmin in distal myop- 

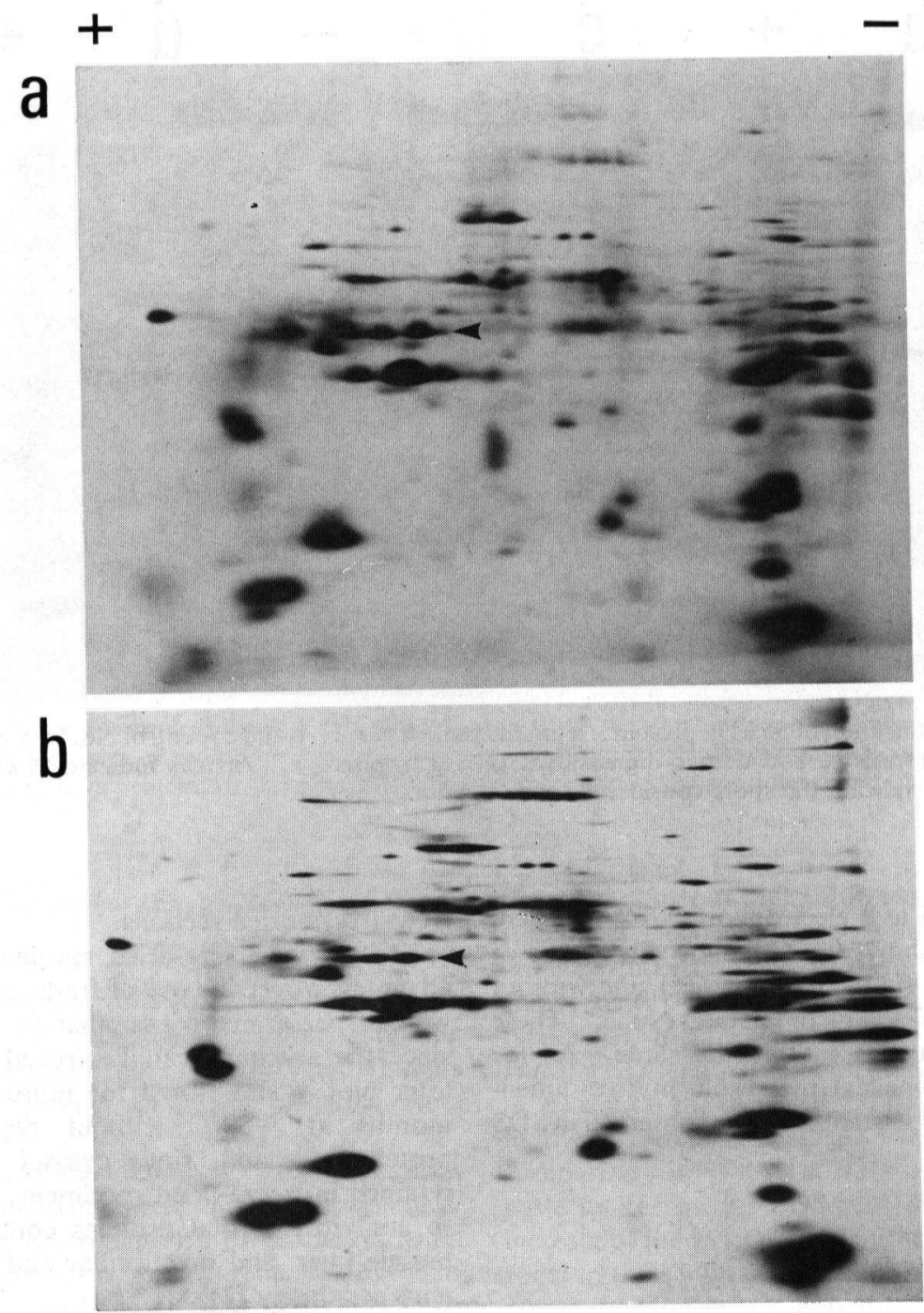

Fig. 5 Comparison of the two-dimensional gel pattern of the muscle fibers with rimmed vacuoles (a) with that of fibers without rimmed vacuoles (b) from patient No. 3. Arrowheads indicate desmin.

athy, chicken dystrophy, and nemaline myopathy has been reported by various authors $(4$, $14,15,22)$.

We gratefully thank Professor M. Satake for much advice and encouragement. Thanks are also due to Dr C. Toyoshima for his critical comments on the manuscript and Mrs N. Takahashi for typing the manuscript. This work was supported in part by grant No. 82-04 from the National Center for Nervous, Mental and Muscular Disorders of the Ministry of Health and Welfare, Tokyo.
Received for publication 20 June 1983; and in revised form 3 August 1983

\section{REFERENCES}

1. Abe T. and SAisu H. (1982) Demonstration of calmodulin-binding proteins in rat brain. Biomedical Res. 3, 207-212

2. Billeter R., Heizmann C. W., Howald H. and JeNNY E. (1981) Analysis of myosin light and heavy chain types in single human skeletal muscle fibers. Eur. J. Biochem. 116, 389-395

3. Dubowitz V, and Brooke M. H. (1973) Muscle 
Biopsy: A Modern Approach, Saunders, London/ Philadelphia/Tronto, pp. 231-241

4. Edström L., Thornell L.-E. and Eriksson A. (1980) A new type of hereditary distal myopathy with characteristic sarcoplasmic bodies and intermediate (skeletin) filaments. J. Neurol. Sci. 47, 171-190

5. Fukuhara N., Kumamoto T. and Tsubaki T. (1980) Rimmed vacuoles. Acta Neuropathol. 51, 229-235

6. Gard D. L. and Lazarides E. (1982) Analysis of desmin and vimentin phosphopeptides in cultured avian myogenic cells and their modulation by 8 -bromo-adenosine 3',5'-cyclic monophosphate. Proc. Natl. Acad. Sci. USA 79, 6912-6916

7. Giometti C. S., Anderson N. G. and Anderson N. L. (1979) Muscle protein analysis. 1. Highresolution two-dimensional electrophoresis of skeletal muscle proteins for analysis of small biopsy samples. Clin. Chem. 25, 1877-1884

8. Ishiura S., Takagi A., Nonaka I. and Sugita M. (1981) Heterogeneous expression of myosin light chain 1 in a human slow-twitch muscle fiber. J. Biochem. 90, 279-282

9. Kratz R. and Brooke M. H. (1979) Distal myopathy. In Handbook of Clinical Neurology 40 (ed. Vinken P. J. and Bruyn G. W.) NorthHolland Pub. Co., Amsterdam, pp. 471-483

10. Kumamoto T., Fukuhara N., Nagashima M., KANDA T. and WaKabayashi M. (1982) Distal myopathy: Histochemical and ultrastructural studies. Arch. Neurol. 39, 367-371

11. Laemmli U. K. (1970) Cleavage of structural proteins during the assembly of the head of bacteriophage T4. Nature 227, 680-685

12. LAZARIDES E. and BALZER D. R.(1978) Specificity of desmin to avian and mammalian muscle cells. Cell 14, 429-438

13. Lowry O. H. and Passonneau J. V. (1972) $A$ Flexible System of Enzymatic Analysis, Academic Press, New York, pp. 223-235

14. Mikawa T., Takeda S., Shimizu T. and Kitaura T. (1981) Gene expression of myofibrillar proteins in single muscle fibers of adult chicken:
Micro two dimensional gel electrophoretic analysis. J. Biochem. 89, 1951-1962

15. Nonaka I., Sunohara N., Ishiura S. and SAtoyoshi E. (1981) Familial distal myopathy with rimmed vacuole and lamellar (myeloid) body formation. J. Neurol. Sci. 51. 141-155

16. OAKley B. R., Kirsch D. R. and Morris N. R. (1980) A simplified ultrasensitive silver stain for detecting proteins in polyacrylamide gels. Analyt. Biochem. 105, 361-363

17. Obinata T., Maruyama K., Sugita H., Kohama K. and Ebashi S. (1981) Dynamic aspects of structural proteins in vertebrate skeletal muscle. Muscle Nerve 4, 456-488

18. O'Farrell P. H. (1975) High resolution twodimensional electrophoresis of proteins. $J$. Biol. Chem. 250, 4007-4021

19. O'Farrell P. Z., Goodman H. M. and O'FarRELL P. H. (1977) High resolution two-dimensional electrophoresis of basic as well as acidic proteins. Cell 12, 1133-1142

20. Petell J. K., Sardo M. J. and Lebherz H. G. (1981) A simple procedure for the isolation of seven abundant muscle enzymes. Preparat. Biochem. 11, 69-89

21. Pette D. and Schnez U. (1977) Coexistence of fast and slow type myosin light chains in single muscle fibres during transformation as induced by long term stimulation. FEBS Lett. 83, 128130

22. Sugita H., Ishiura S., Nonaka I., Ohashi K. and Maruyama K. (1981) Gel electrophoretic study of nemaline muscle. Proc. Japan Acad. B 57, 59-63

23. Tanaka K., Yuasa T., Kumamoto T., FukuHARA N. and Kondo K. (1982) A case of KearnsSayre-like syndrome associated with rimmed vacuoles. Clin. Neurol. (Tokyo) 22, 1015-1020

24. Weeds A. G., Hall R. and Spurway N. C. S. (1975) Characterization of myosin light chains from histochemically identified fibres of rabbit psoas muscle. FEBS Lett. 49, 320-324

25. Young O. A. and Davey C. L. (1981) Electrophoretic analysis of proteins from single bovine muscle fibres. Biochem. J. 195, 317-327 